\title{
NASA Ares I Crew Launch Vehicle Upper Stage Overview
}

\author{
Daniel J. Davis \\ Ares I Upper Stage Manager \\ National Aeronautics and Space Administration \\ Marshall Space Flight Center, Alabama 35812 \\ J. Craig McArthur \\ Ares I Upper Stage Deputy \\ National Aeronautics and Space Administration \\ Marshall Space Flight Center, Alabama 35812
}

\begin{abstract}
By incorporating rigorous engineering practices, innovative manufacturing processes and test techniques, a unique multi-center government/contractor partnership, and a clean-sheet design developed around the primary requirements for the International Space Station (ISS) and Lunar missions, the Upper Stage Element of NASA's Crew Launch Vehicle (CLV), the “Ares I," is a vital part of the Constellation Program's transportation system.
\end{abstract}

\section{Introduction}

The NASA Constellation Program's exploration missions will include an Ares I Crew Launch Vehicle (CLV) and Ares V Cargo Launch Vehicle (CaLV) required to place crew and cargo in low-Earth orbit (LEO), crew and cargo transportation systems required for human space travel, and transportation systems and scientific equipment required for human exploration of the Moon and Mars. Early Ares I configurations will support International Space Station (ISS) re-supply missions.

A self-supporting cylindrical structure, the Ares I Upper Stage will be approximately 84' long and 18 ' in diameter. The Upper Stage Element is being designed for increased supportability (reducing the logistics footprint) and increased reliability to meet human-rating requirements imposed by NASA standards. The design also incorporates state-of-the-art materials, hardware, design, and integrated logistics planning, thus facilitating a supportable, reliable, and operable system.

With NASA retiring the Space Shuttle fleet in 2010, the success of the Ares I Project is essential to America's continued leadership in space. The first Ares I test flight, called Ares 1-X, is scheduled for 2009. Subsequent test flights will continue thereafter, with the first crewed flight of the Crew Exploration Vehicle (CEV), “Orion,” planned for no later than 2015. Crew transportation to the ISS will follow within the same decade, and the first Lunar excursion is scheduled for the 2020 timeframe.

American Institute of Aeronautics and Astronautics 


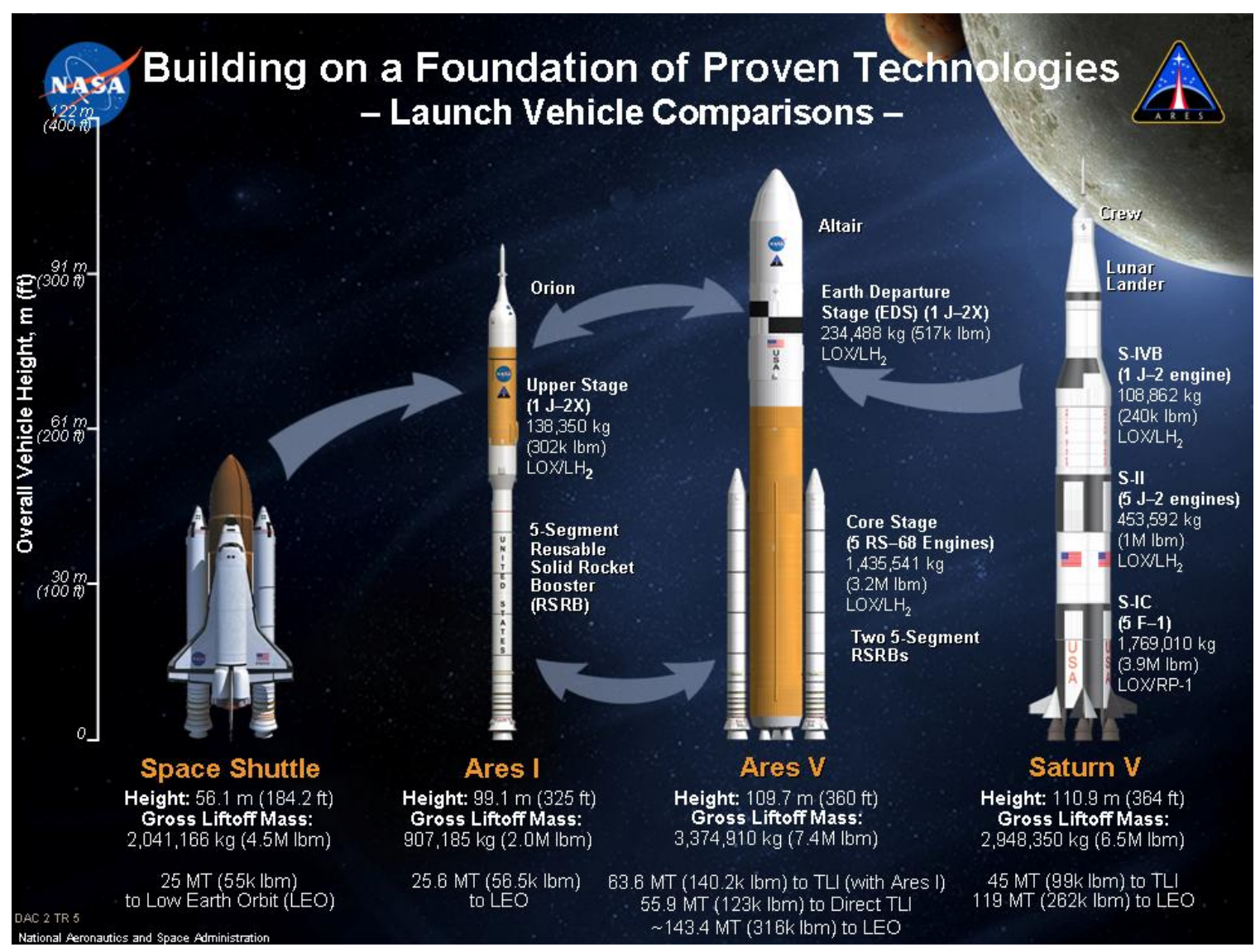

Figure 1. Heritage to Development Comparison.

The Ares I Upper Stage is being designed by a NASA Design Team (NDT) and fabricated by the Upper Stage Production Contractor (USPC), The Boeing Company, at the Michoud Assembly Facility (MAF) in New Orleans, Louisiana. NASA awarded this contract to Boeing in August 2007 in a competitive procurement as part of an agreement that includes the assembly, checkout, and delivery of the completed integrated Upper Stage. NASA also solicited for an Upper Stage Instrument Unit Avionics Contractor (IUAC) to fabricate, assemble, and checkout the avionics hardware and systems into the Instrument Unit (IU). The Agency awarded this contract to Boeing in 2007.

The Upper Stage Office (USO) at Marshall Space Flight Center (MSFC) is responsible for the Upper Stage Design, Development, Test, and Evaluation (DDT\&E), including project management, development planning, resource planning, tracking, and risk management. The USO is also responsible for the qualification acceptance of flight hardware. NASA will maintain data rights for the design and resulting Upper Stage hardware. The DDT\&E period consists of the first five test flights of the Ares I-Ares 1-X, Ares 1-Y, Orion 1, Orion 2 (crewed), and Orion 3 (crewed). The USO employs a low-cost strategy that maximizes price competition and emphasizes total cost of ownership early in the design cycle. Safety is also emphasized in all phases of design and production. 


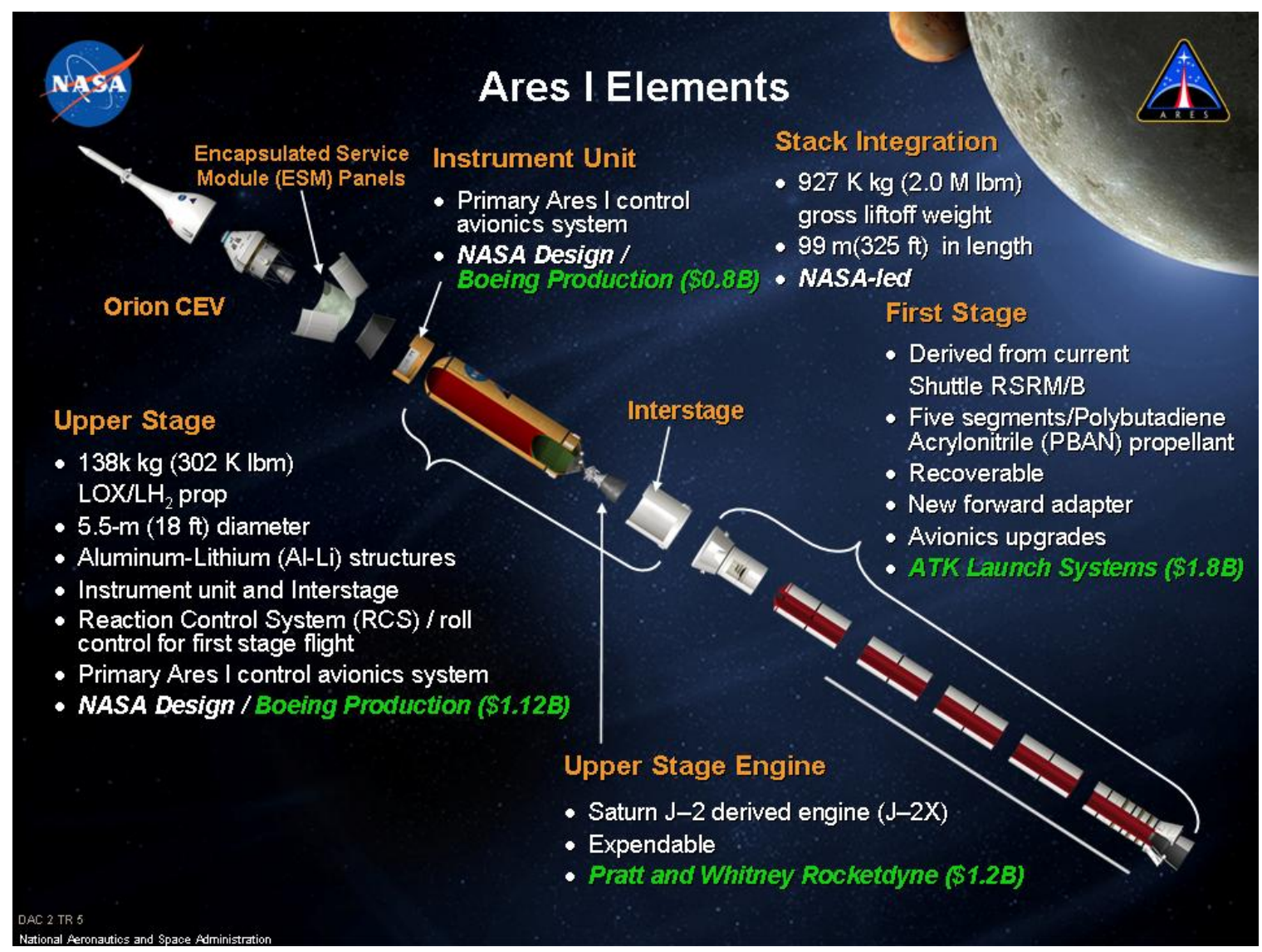

Figure 2. Upper Stage Overview.

\section{Upper Stage Element Functional Overview}

The Upper Stage will provide the guidance, navigation, and control (GN\&C), and the Saturnderived J-2X Upper Stage Engine (USE) will provide the thrust and propulsive impulse, required for the second stage of the Ares I ascent flight after the First Stage separates from the launch vehicle.

The baseline Design Reference Mission calls for the Upper Stage to provide active thrust via the USE for approximately 463 seconds after First Stage burnout and separation. Shortly after USE cut-off, the Orion CEV separates from the Upper Stage and ignites for insertion into LEO. The Upper Stage is dormant after safe shut-down of the USE and re-enters for disposal in the Indian Ocean. The two Design Reference Mission trajectories envisioned for the Ares I launch vehicle are a $28.5^{\circ}$ flight profile to support Lunar missions and a $51.6^{\circ}$ flight profile to support ISS missions.

Figure 3 illustrates the primary products of the Upper Stage Element. 


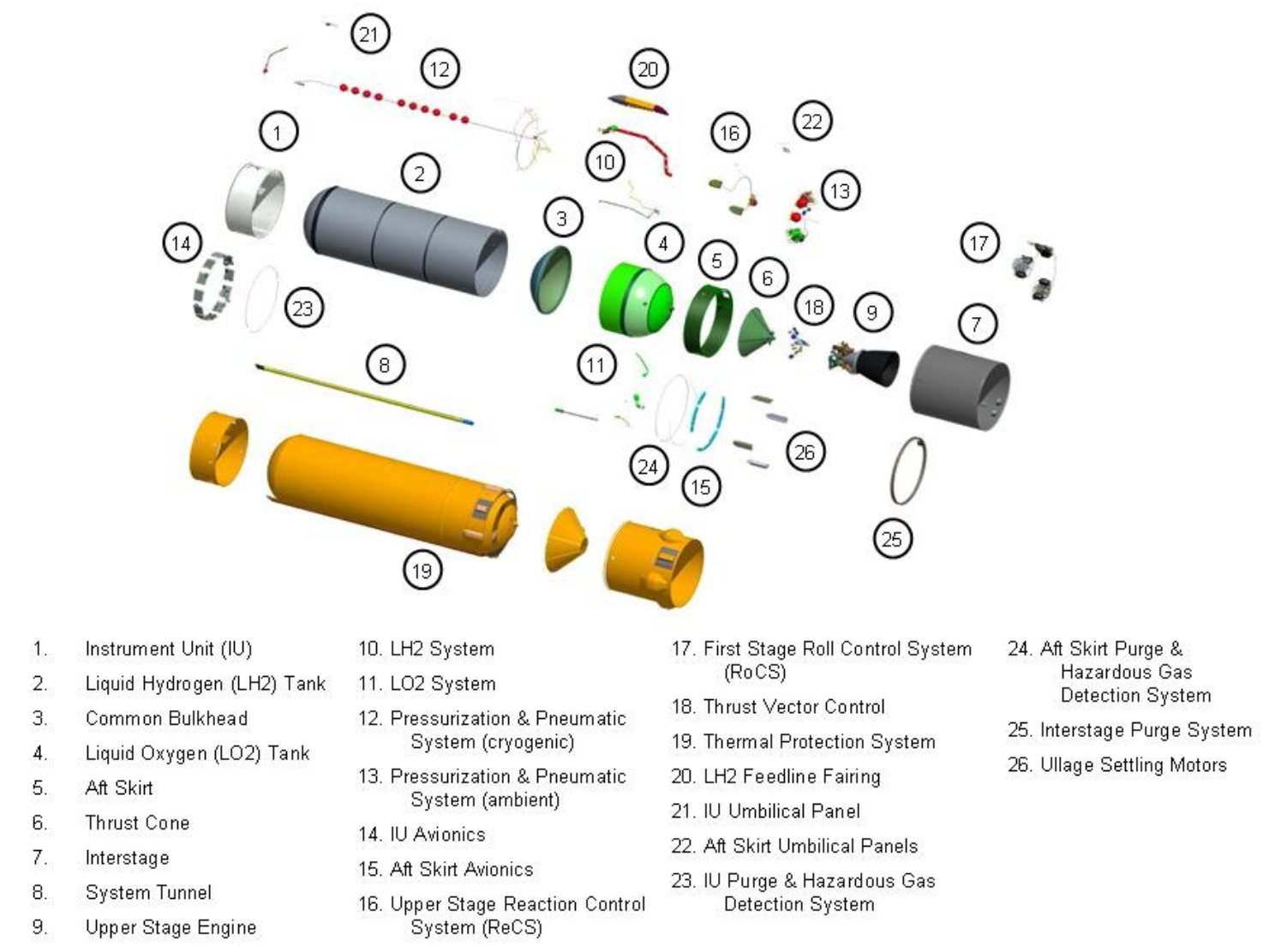

Figure 3. Upper Stage Element.

The Upper Stage Element is responsible for delivering a certified avionics system for the Ares I during all program phases of ground processing and flight. This responsibility includes all supporting ground infrastructure, facilities, hardware, and software necessary for design, development, test, checkout, and production. The IU will be the primary location for the avionics systems; however, some avionics will be located in other areas of the Upper Stage, including the Aft Skirt, Interstage, and Thrust Cone. The avionics system is composed of all electronic hardware required for ground processing and checkout, as well as in-flight vehicle Guidance, Navigation, and Control (GN\&C); command and data handling; and pre-flight checkout.

The final integrated Ares I Upper Stage will be the product of numerous partnerships among industry participants, the USPC and IUAC, and multiple NASA Centers. The development process begins with component tests and advances to more integrated testing as the design matures. The design is managed in Design Analysis Cycles (DACs) that provide coordinated decomposition, detailed design at the component level, and reintegration of the system. The DACs are scheduled to support design reviews.

Development of the Upper Stage is a partnership between MSFC, Kennedy Space Center (KSC), Glenn Research Center (GRC), Langley Research Center (LaRC), Ames Research Center (ARC), Stennis Space Center (SSC), and Johnson Space Center (JSC). MSFC has the project management and development responsibility, and MAF will be used to manufacture and assemble vehicle hardware. The project also works closely with a number of Aerospace and Manufacturing industry leaders. 


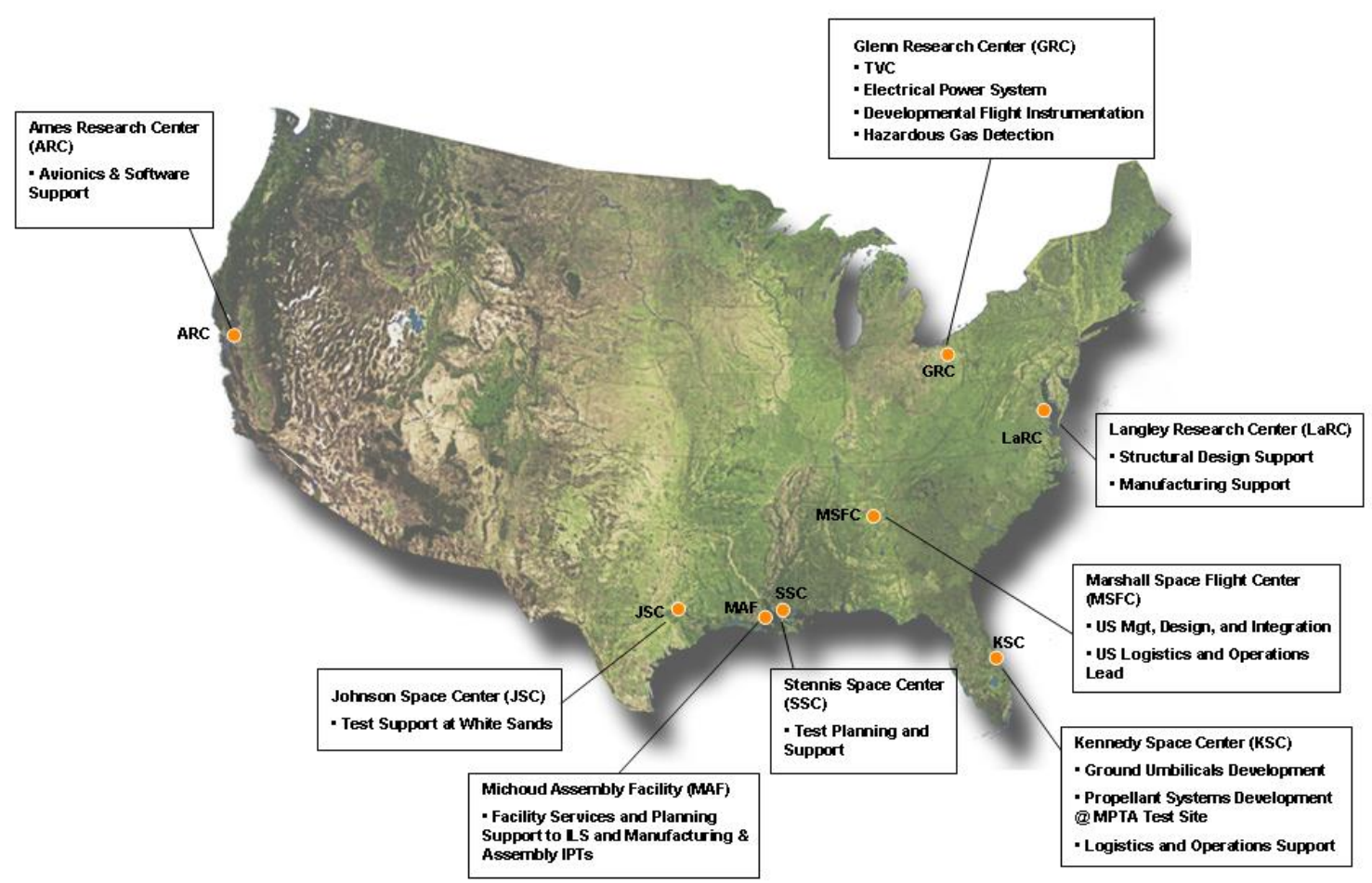

Figure 4. Upper Stage Development Approach.

\section{Successful Reviews}

In 2007, the Upper Stage Element successfully completed a System Requirements Review (SRR) and System Definition Review (SDR). The SRR, completed in April 2007, confirmed that 1) the Upper Stage Element requirements were complete, verifiable, properly flowed down and traceable, validated, allocated to the subsystem level, and ready to be placed under configuration control; 2) associated risks were identified with mitigations; 3 ) the requirements were responsive to mission requirements and the architecture/design concept could fulfill the mission objectives within imposed constraints; and 4) the Upper Stage Element was of sufficient maturity to warrant moving forward to the next phase of development and the SDR. Upper Stage Subsystems, including Avionics \& Software and Main Propulsion System (MPS), have also successfully completed their respective Subsystem SRRs.

The SDR, completed in October 2007, evaluated the element-level design against the current set of baseline element requirements. The Upper Stage Team openly presented and discussed actions and forward work to close out all Upper Stage SDR Pre-Board findings, with the Board concurring on proceeding to Upper Stage Preliminary Design Review (PDR).

The requirements phase is followed by the preliminary design phase, which will be completed in August 2008 with the PDR for the Upper Stage Element. PDRs for each of the Upper Stage subsystems were completed in May 2008. Subsystem components are being fabricated and procured during this phase to support the development phase design and test activities.

Upon completion of the PDRs, the Element will enter the final flight design phase, culminating with the Critical Design Reviews (CDRs) in November 2009, at which point the Upper Stage flight configuration design will be baselined. After completion of the CDRs, flight configuration hardware fabrication to support component-level design qualification testing, systems-level design qualification, and 
flight system fabrication and assembly will begin. All flight configuration hardware, including all qualification hardware, will be fabricated to released drawings.

\section{Innovative Technologies}

The current version of the Space Shuttle's External Tank (ET) uses a 2195 Aluminum-Lithium (Al-Li) alloy, which can be welded and withstands fractures to a temperature of minus 423 degrees-the temperature at which the Liquid Hydrogen (LH2) propellant is stored on board. The Ares I Upper Stage will use Al-Li alloy tanks with external insulation to contain the Liquid Oxygen (LOX) and LH2 propellants. The Upper Stage IU, Thrust Cone, and Umbilical Plates will also be fabricated from Al-Li 2195. The Upper Stage Common Bulkhead will be manufactured from Al-Li 2219.

An innovative self-reacting Friction Stir Welding process, used successfully on the Shuttle's External Tank (ET) Project, will also be used on the Ares I Upper Stage. Friction Stir Welding transforms the Al-Li alloy from a solid state into a "plastic-like" state, and then methodically stirs the materials together under pressure to form a welded joint. The advantages of using the self-reacting Friction Stir Welding process include the ability to join materials previously considered "unweldable," and the improvement of properties relative to the fusion welding process. Self-reacting Friction Stir Welding also has the added advantages of requiring simplified tooling and no anvil, and has the potential for lower defects and faster travel rates than conventional Friction Stir Welding processes.

Additionally, a Robotic Weld Tool at MSFC is now welding test panels for the Ares I Upper Stage. Once startup issues are resolved, welding of sample ET dome gores will begin, and will serve as a high-fidelity checkout of robot operation. Follow-on operations will include installation of Upper Stage dome welding prototype tooling, and welding of gores and Y-rings for manufacturing demonstration and structural development test articles at MSFC.

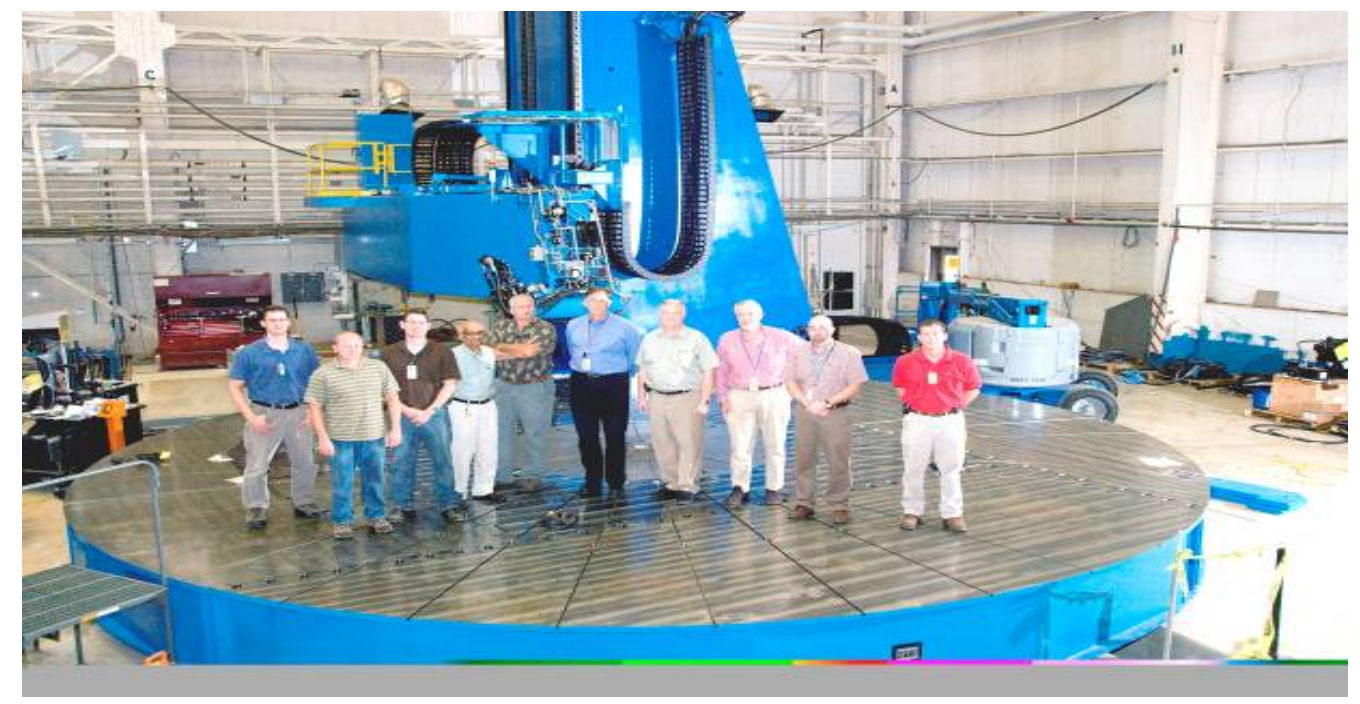

Figure 5. Robotic Weld Tool now in operation at MSFC.

The first foam spray at MSFC in support of the Ares I Upper Stage has also been completed. The system was set up to develop and qualify thermal protection foam for application to Upper Stage cryogenic systems. Because the Space Shuttle heritage foam systems use chloroflorocarbons that will be outlawed after 2015, the Upper Stage foams will use non-ozone-depleting blowing agents. The next steps for this facility are to screen candidate materials, then develop the best candidates for the various applications on the Upper Stage. The result should be Thermal Protection Systems materials with environmentallycompliant components. 

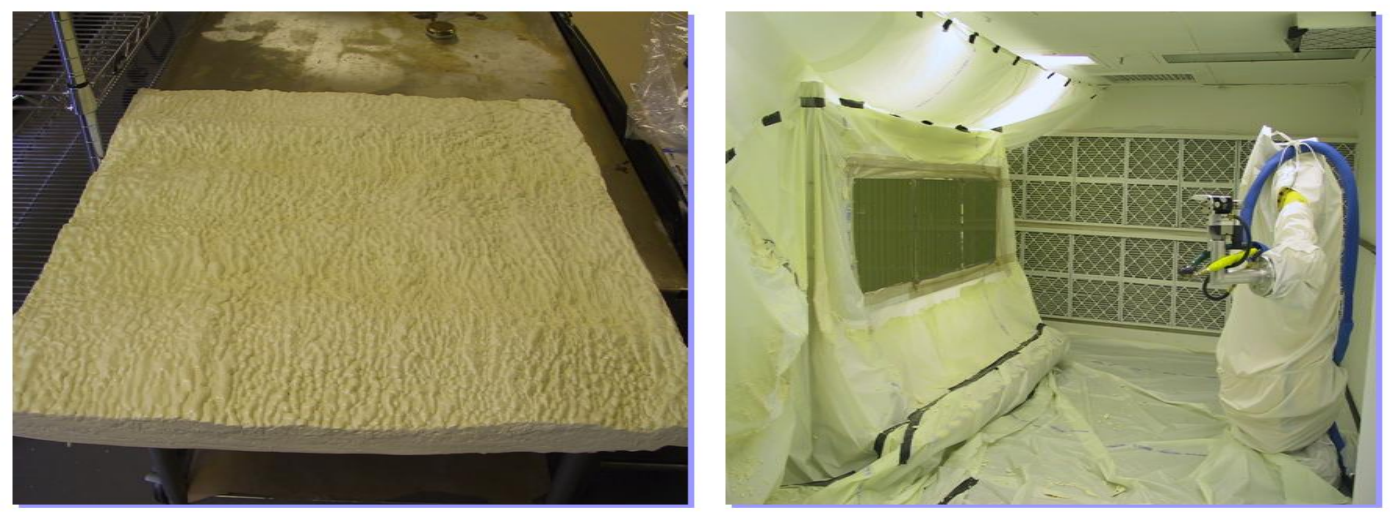

Figure 6. First Upper Stage Foam Panels Sprayed at MSFC.

\section{Structural Development Highlights}

Ares I Upper Stage Structural Development test efforts are also continuing for small panel Al-Li buckling tests. The purpose of these tests is to characterize the behavior of compression-loaded orthogrid panels for strength and stability, as well as correlate, through analytical approaches, with the instrumentation data and photogrammetry. Testing is similar to previous testing performed by Lockheed Martin of MAF for the Shuttle ET Project. Test support equipment from the previous testing of ET panels was modified to support this test series, which was established as developmental (there are no program or qualification requirements to be verified) to provide lessons learned prior to initiating future test series involving larger panels and flight qualification test articles.

The Structural Test Plan for these initial tests calls for five monocoque panels to be tested by applying a compressive load through the test fixturing until a failure is identified or a maximum load is reached, or the Test Requester stops the test. A successful test is one in which the test article is loaded to failure or maximum load and data was obtained for correlation purposes.

This testing is conducted in the Gilmore Universal Test Machine in the Load Test Annex Extension at MSFC (see Figure 7), and will be followed by Composite Panel Testing, Common Bulkhead Development Testing, and Interstage and IU Qualification Testing.

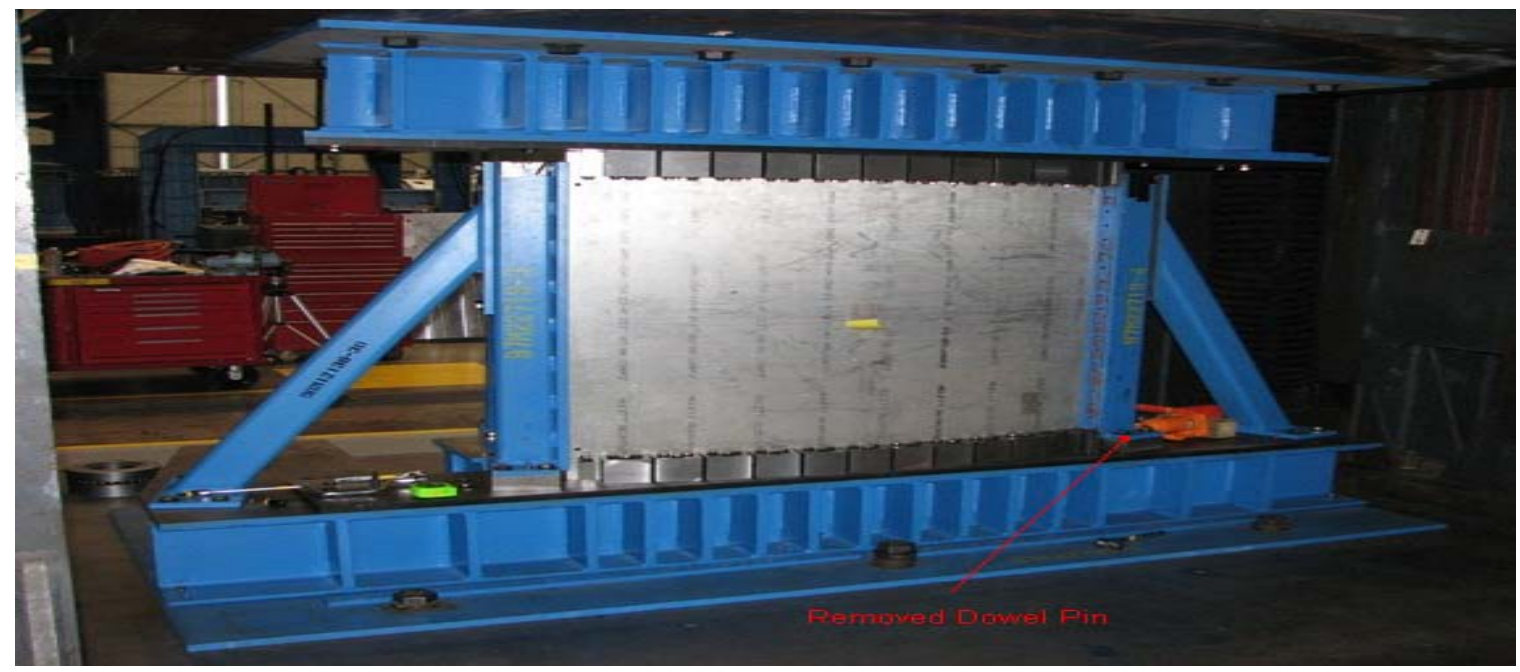

Figure 7. Monocoque Test Panel Installed In Gilmore.

American Institute of Aeronautics and Astronautics 
In addition to Structural Development testing, the Upper Stage Structures and Thermal subsystem has also conducted a series of Final Layout Reviews (FLORs) for each of the Upper Stage structural components. Each FLOR included layout drawings, detailed part drawings, and a design analysis notebook. Immediately following a layout review, a virtual design review was held, during which the 3-D model of the component was reviewed by NDT member and Ares I Program Management by looking at interfaces, clearances, routing, and assembly. These FLORs were critical activities in preparing for the Upper Stage PDR.

\section{Other Upper Stage Test Highlights}

The Upper Stage Small Solids team is also preparing to conduct the first Heavy Weight Motor (HWM) test for the Ullage Settling Motor (USM) propellant at MSFC. The USM system ensures that ullage is maintained at the forward tank dome during J-2X ignition. The system encompasses all functions required to fire the USMs and eject them from the Upper Stage aft skirt. The purpose of the test is to validate the performance of the USM propellant, propellant grain structure, and propellant geometry for the Ares I. The HWM insulated case and nozzle are provided by the U.S. Army's Aviation and Missile Research, Development, and Engineering Center (AMRDEC). After data review and acceptance of the design, fabrication and checkout of special NASA HWM tooling is completed, and an Operations Readiness Safety Inspection is performed, the liner will be applied to the insulated case, and final cast, cure, and finish propellant grain will occur. The motor is then installed in the MSFC test stand for static test firing. Using MSFC thrust stand and Data Acquisition System, vital performance data will be obtained for the USM propellant design.

The first hot-fire test of the USM igniter was recently conducted in MSFC Test Stand Area 116. Test results showed that the igniter trace was on target and the igniter is extremely overbuilt; due to the life cycle phase of the project, this was good news for the team. Future testing will involve an additional 22 igniters being made at Sierra-Lobo and to be delivered to MSFC.
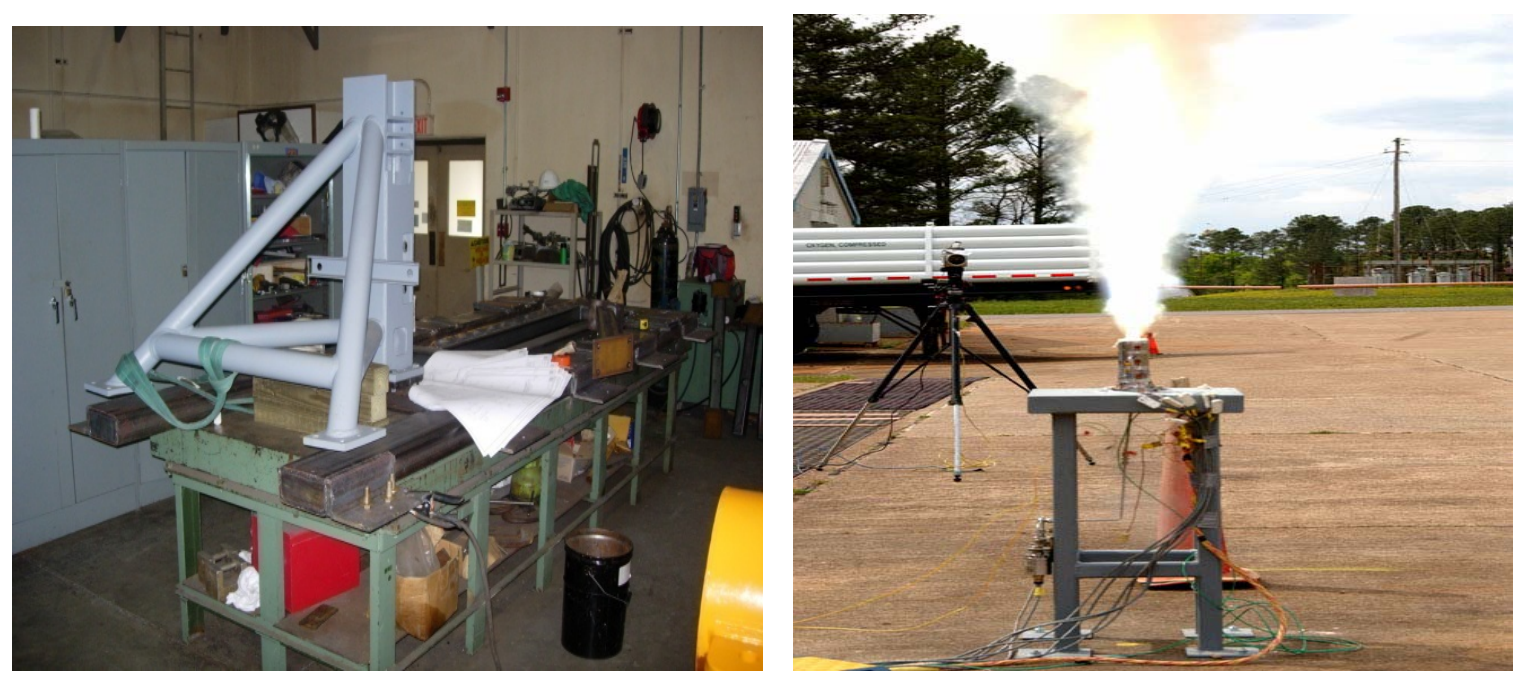

Figure 8. (L-R) Test Stand Adapter for HWM Test and First USM Igniter Hot-Fire.

Other Upper Stage subsystems are also involved in rigorous testing and analysis as the Element proceeds to PDR. These include Thrust Vector Control Hydraulic Breadboard testing; Reaction Control System RCS Water Hammer testing; and Main Propulsion System Cryo-regulator testing and Bench testing of Saturn components. 


\section{Conclusion}

In the early days of the Saturn era, President John F. Kennedy was fond of paraphrasing the Irish writer Frank O'Connor by saying, “This Nation has tossed its cap over the wall of space, and we have no choice but to follow it." As NASA celebrates its $50^{\text {th }}$ Anniversary in 2008, the United States again finds itself on the cusp of another glorious era of space exploration. To accomplish its goals, the Ares I team must build beyond its current capability to ferry astronauts and cargo to LEO. And to reach for Mars and beyond, the team must first reach for the Moon.

The NASA and Boeing Upper Stage teams are now integrated, working together, and making good progress. They are designing and building the Ares I Upper Stage by using extensive lessons learned to minimize cost, technical, and schedule risks. Today this Nation, like the space pioneers of the 1960s, has once again tossed its cap over the wall of space. We have no choice but to follow it.

American Institute of Aeronautics and Astronautics 